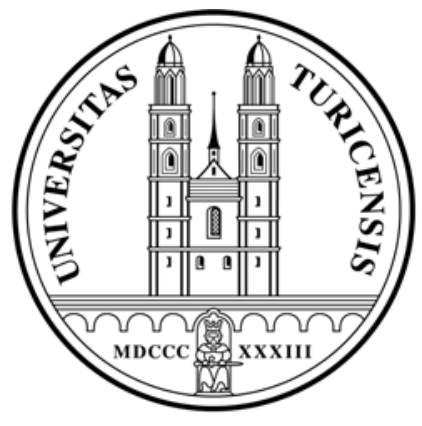

Institute for Empirical Research in Economics

University of Zurich

Working Paper Series

ISSN 1424-0459

Working Paper No. 288

\title{
Environmental Morale and Motivation
}

Bruno S. Frey and Alois Stutzer

April 2006 


\title{
EnVironmental Morale AND Motivation
}

\author{
Bruno S. Frey and Alois Stutzer ${ }^{\square}$ \\ (University of Zurich)
}

April 25, 2006

\begin{abstract}
This chapter discusses the role of environmental morale and environmental motivation in individual behavior from the point of view of economics and psychology. It deals with the fundamental public good problem, and presents empirical (laboratory and field) evidence on how the cooperation problem can be overcome. Four different theoretical approaches are distinguished according to how individuals' underlying environmental motivation is modeled. Specifically, we look at the interaction between environmental policy and environmental morale through the lens of cognitive evaluation theory (also known as crowding theory).
\end{abstract}

JEL classification: D64, H41, Q50, Z13

Keywords: environmental morale, environmental policy, motivation crowding, pro-social preferences, public good problem

\footnotetext{
$\square$ Institute for Empirical Research in Economics, University of Zurich, Bluemlisalpstrasse 10, CH8006 Zurich, Switzerland and CREMA - Center for Research in Economics, Management and the Arts. Phone: +41-44-634 37 30, Fax: +41-44-634 49 07, Email: bsfrey@iew.unizh.ch, astutzer@iew.unizh.ch.
} 


\section{Why is Environmental Morale Important?}

Economists are convinced that mankind has the capacity to overcome environmental problems if only the right incentives are in place. The environmental problem is identified to lie in the externalities inducing people to destroy the environment because such action is free of cost. The solution is to establish property rights ensuring that every user of the services provided by the environment must pay an appropriate price. The policy instruments suggested rely on an imitation of markets via tradeable licenses, or environmental taxes and subsidies. The relative price effect (see Becker 1976, Frey 1992a) ensures that an efficient allocation of all resources, produced and natural, is achieved. These instruments alone are sufficient to reach that goal provided they are correctly applied; no other instruments are needed. There is by now a large literature on environmental economics buttressing this view (see e.g. the surveys by Cropper and Oates 1992 and Stavins 2005), and there are impressive examples of the effectiveness of using the price system (e.g. Diekmann and Preisendörfer 2003). A large majority of economists has no doubt that using incentive instruments is far superior to relying on either moralistic behavior, or on commands and controls. Environmental economics has indeed been identified as one of the most successful applications of economic theory (Faulhaber and Baumol 1988).

In contrast to economists, most psychologists take it as a matter of course that in order to successfully address environmental issues people must change their way of thinking and must adopt "environmental values". Economists criticize this approach as having little or no impact on the environment. On the other hand, the use of market incentive instruments is put into doubt by many social scientists and environmental activists. They argue that today's society cannot rightfully sell what it does not own because nature is taken to have rights of its own and also belongs to future generations. Moreover, rationing the scarce environmental resources by prices is often taken to be unfair.

The two approaches take extreme positions; environmental morale is certainly more important than claimed in standard economics. An environmental policy solely using price incentives disregards the useful contribution of environmental morale and motivation to overcome environmental degradation.

The damage to the environment created by the activity of human beings is, to a large extent, due to public good or free riding problems: While each person values a better state of the 
environment, conditions are such that it is advantageous for each individual not to contribute to this improvement. In four specific areas, it is possible only to overcome this cooperation problem if the population has a sufficient degree of environmental morale:

(1) In important areas, economic incentive instruments cannot be applied at all or would be too costly to overcome cooperation problems (see Baumol and Oates 1979). This is the case when the costs of control are extremely high due to many diffuse sources of pollution, or due to a large number of individuals causing environmental damage in small ways (e.g. spitting, throwing away batteries, pieces of paper or used cigarettes). In these cases voluntary contributions must be relied upon in order to prevent negative environmental externalities.

(2) The provision of environmental public goods has often to be secured by people willing to sanction non-contributors. Sanctioning involves costs over and above individuals' direct voluntary contributions to a public environmental good. Monitoring, complaining, shaming or even punishing at one's own cost involves another public good (a second order public good). For its provision, individuals must have a preference for reciprocal fairness in environmental issues.

(3) Extensive empirical research shows that controls and punishment are only one factor inducing people to observe existing laws and regulations. The subjective expected utility model used by standard economics is unable to explain in a satisfactory way how people actually behave (Schoemaker 1982). An important factor why people obey the law is the morally based inclination to act legally when the laws are perceived to be "fair" and "legitimate" (Tyler 1990).

(4) The economic instruments of environmental policy can only be politically applied if the citizens are prepared to support the public good of environmental protection when voting. As no single person can determine the collective decision (it depends on the votes of many thousands or even millions of other citizens) he or she has little or no incentive to cast a vote in favor of the environment especially when his or her private interests are negatively affected. A collective decision for the environment requires that a majority of the voters has an intrinsic motivation to protect the environment, and to therefore politically support the proposed environmental policy.

This contribution discusses the role of environmental morale and environmental motivation in individual behavior from the point of view of economics and psychology. Section II deals 
with the fundamental public good problem, and presents empirical (laboratory and field) evidence on how the cooperation problem can be overcome. Four different theoretical approaches are distinguished according to how individuals' underlying environmental motivation is modeled. The following section III looks specifically at the interaction between environmental policy and environmental morale through the lens of cognitive evaluation theory (also known as crowding theory). Section IV concludes.

\section{The Public Good Problem in the Natural Environment}

\section{A. Standard Prediction versus Experimental Evidence}

Rational, self-interested individuals do not contribute to a public good or the conservation of a common pool resource. This is the outcome of the n-person prisoner's dilemma game viewed as the canonical representation of the public good problem (Olson 1965, Hardin 1971). The reason for this predicted outcome is the free rider problem: Public goods are defined as goods from which any agent can benefit independently of her or his own contribution (nonexclusion condition). Accordingly, everybody has an incentive to hope that other agents provide the public good. Narrowly self-interested agents only contribute to the extent that her or his private marginal benefits equal the marginal costs of the public good, whereas it would be optimal for a group if the sum of marginal benefits equates marginal costs. This tension between individual and collective rationality lies at the heart of many cooperation problems.

This outcome contradicts, however, both laboratory experiments and observations of everyday life. In particular, there is substantial evidence from linear public goods games (or voluntary contribution mechanisms), the game that has probably most often been used to study the incentive to free ride. The game can be summarized as follows: "In a typical linear public goods experiment, $n$ people form a group. All group members are endowed with $z$ “tokens". Each subject $i$ has to decide independently how many tokens (between 0 and $z$ ) to contribute to a common project (the public good). The contributions of the whole group are summed up. The experimenter then multiplies the sum of contributions by $\square>1$ and distributes the resulting amount equally among the four group members" (Gächter 2006: 4). This game has been implemented in many different versions (one-shot versus repeated interaction, with and without identification of fellow agents, with and without a possibility to punish other group members for non-contribution etc.). 
Seven general findings summarize the core results of this experiment and similar others (see Ledyard 1995, Ostrom 2000):

(1) The contribution by individuals is between 40 and 60 percent of their endowment in oneshot and in the first round of finitely repeated games.

(2) While in the course of successive rounds the contribution levels fall, they remain above zero.

(3) If people are grouped in fixed pairs and interact repeatedly with the same "partner", they contribute more than if they interact with a randomly chosen fellow agent (see Keser and van Winden 2000, Andreoni and Croson 2008).

(4) People can learn to (strategically) cooperate at a moderate level for longer periods of time, in particular with repeated interaction with the same people.

(5) Individuals who believe that others will contribute to a public good tend to contribute more themselves (see also Frey and Meier 2004, Gächter 2006). This finding suggests that agents' contributions depend on what they expect others to do; or that they behave to some extent as conditional cooperators.

(6) Individuals are prepared to cooperate much more with face-to-face identification and communication (see also Bohnet and Frey 1999).

(7) Players are willing to incur costs to punish those who make below average contributions to a public good (see also Fehr and Gächter 2000).

These experimental results have also been observed in many everyday life contexts. Thus, many people contribute to voluntary associations (Meier 2006), do not cheat on taxes even if they could (Feld and Frey 2002) and vote. These empirical findings have only partly been well integrated into theory. There is still a substantial gap between the (game) theoretic prediction that self-interested individuals do not contribute to a public good and the empirical observation that cooperative behavior is widespread.

\section{B. Model Approaches to Environmental Morale and Motivation}

Theoretical research has explored various ways to meet the challenge. Four important approaches can be distinguished to model individuals' underlying motivation to contribute to public environmental goods (or to model moral or norm-based behavior in general):

- altruism,

- social norms and reciprocal fairness,

- internalized norms, and 
- intrinsic motivation.

Pure altruism as a type of pro-social preference means in the public goods context that an individual values an increase in the provision of the public good positively because (i) she has private preferences for it, and (ii) additional resources are allocated to a relevant reference agent, i.e. she wants to benefit others (e.g. Andreoni 1988). Pure altruism, however, appears to be counterfactual in most situations as a sole explanation for contributions to a public good. The reason being people's observed reactions in their giving behavior to state subsidies. In the pure altruism model, contributions depend on the utility level achieved by their fellow agents. People contribute more to a public good when the utility level of fellow agents is lower. This also implies that voluntary contributions to a public good are reduced if, e.g., the state starts subsidizing or providing the good. In fact, a crowding out Euro for Euro by state subsidies is predicted. This is the traditional crowding effect (not to be mixed up with motivation crowding introduced in the next section). Empirical evidence for people's reactions to state subsidies in the voluntary contributions, however, shows no full crowding-out (see Nyborg and Rege 2003 for a brief overview).

An extended model of impure altruism has been proposed (Andreoni 1990) in order to reconcile altruistic giving or contributing to a public good with the empirical findings. If people get a positive feeling from contributing itself, no full crowding out is implied. This pro-social preference is called a preference for "warm glow". It is important to note, however, that the later model of altruism can also not account for some of the robust findings about voluntary contributions mentioned above. In particular, altruistic motives are either independent of other people's cooperation behavior or predict lower contributions if others contribute.

Social norms can be understood as socially shared beliefs about how one ought to behave, e.g. contributing to a public good. The prescribed behavior is enforced by informal social sanctions. It is argued that social norms can be understood as a reaction by societies to overcome market failure like in a public good situation (e.g. Arrow 1971). While with impure altruism warm glow is the by-product of contributing, the by-product of following a social norm is social approval or the avoidance of disapproval (e.g. Holländer 1990, Gächter and Fehr 1999). Social norms for "environmental friendly" behavior can be issue specific (e.g. against littering the street) or refer in general to behavior in a public goods context (Biel et al. 1999, Kerr 1995). Probably theoretically more important than the specific content of norms is their enforcement. Thereby, reciprocal fairness takes a key role as a norm enforcement device 
(Fehr and Gächter 2000b). Reciprocal fairness or reciprocity means that an individual responds to an action that is perceived to be kind or fair in a kind matter, and to an action that is perceived as hostile or unfair in a hostile manner. The perceived kindness, fairness or hostility of an action depends on the outcomes, intentions and procedural qualities associated with the action (for a model of reciprocity see, e.g., Falk and Fischbacher 2006).

Internalized norms differ from social norms by the nature of rewards and sanctions as a reaction to individual behavior. If a norm is internalized, sanctions are internal and result in feelings of guilt, reduced self-respect and other negative self-evaluations. ${ }^{1}$

Intrinsic motivation with regard to contributing to public goods means that people pursue an activity for the inherent satisfaction of the activity itself (Ryan and Deci 2000). In contrast, extrinsic motivation "refers to the performance of an activity in order to attain some separable outcome" (Ryan and Deci 2000, p. 71). It might be argued that most environmentally desirable behavior is motivated by the expectation of separable outcomes and thus pro-social behavior in the environmental realm is rarely intrinsic in the narrow meaning of the term. However, the differences are subtle, in particular with regard to internalized norms. With internalized norms, people feel an obligation or a commitment to contribute and nonperformance results in negative feelings (e.g. Schwartz 1977). The two approaches converge to the extent that internalized norms are derived from the person's internalized values (Schwartz and Howard 1984, and for the case of pro-environmental action Stern et al. 1995, 1999). It is not anticipated guilt or pride then that motivates cooperation but an intrinsic motivation to act according to one's values. The degree of internalization can be understood to determine the extent to which individuals perceive autonomy in their behavior. This might serve as a conceptual link between norm theories and cognitive evaluation theory. Moreover, it indicates the broader application of motivational crowding theory outlined in section III.

\section{Conditions for Successful Cooperation}

It is very difficult to disentangle the different motives and the kind of social interaction in concrete social dilemmas (Manski 2000). Often individual behavior is determined by several motives simultaneously or different motives matter for different people in the same context (Thogersen 2006). The identification of pre-conditions for successful cooperation is thus a major challenge. Some recent evidence is from laboratory experiments. It is found that

\footnotetext{
${ }^{1}$ The relationship between norms, their internalization and the composition of intrinsic motivation is described in Coleman (1990/1991).
} 
cooperation can be sustained even if there is a large fraction of agents with a tendency to freeride in a group. This is the case, if other agents in the group are motivated to voluntarily contribute and in addition to reciprocally punish free-riders at their own cost. Narrowly selfinterested agents are then provided incentives to contribute to public goods as well. The composition of groups who have to solve a cooperation problem as well as their possibilities to punish fellow agents can thus become crucial (Gächter 2006).

The management of commons offers interesting field evidence with regard to the environment. In extensive empirical research Ostrom and co-workers (2000) have been able to identify the conditions under which people are able to organize a scarce resource even though everyone has an incentive not to contribute to its maintenance, examples being a fish pond or a cow pasture (common-pool resource). A successful organization is the more likely when:

- $\quad$ the resource users are able to design their own rules;

- $\quad$ the rules are enforced by the local users;

- $\quad$ the sanctions applied are graduated;

- the better defined the rights to withdraw from the resources are;

- the more the collective action and monitoring reinforce each other.

These conditions make clear that environmental morale alone does not suffice. Rather, it is necessary that such morale is embedded in an appropriate institutional setting including sanctions - but such sanctions are the most effective when they are voluntarily agreed by the users before the environment has been damaged.

\section{Motivational Crowding Theory and the Interaction between Environmental Policy and Environmental Morale}

\section{A. Theoretical Issues}

Environmental morale can be understood as a conglomerate of internalized norms and intrinsic motivation. It is not given but depends on a great many factors. A crucial question is how intrinsic motivation and internalized norms (here intrinsic motivation for short) are influenced by extrinsic motivation. This is particularly important for environmental policy with its interventions from outside in the form of commands and controls (as in the traditional policy) or in the form of induced price changes (as in the market based economic approach). These issues have been analyzed in "Motivational Crowding Theory" which stems from social 
psychology and has been integrated into economics (Frey 1992b, 1997b, Le Grand 2003, Bénabou and Tirole 2003).

Social psychologists have analyzed and empirically measured the 'hidden cost of reward' (see e.g. Deci and Ryan 1985, Pittman and Heller 1987) suggesting that an external intervention in the form of a reward may reduce individuals' intrinsic incentives to act. This crowding-out effect can be attributed to two major psychological processes.

(1) Self-determination is reduced. When people perceive an external intervention as a restriction to act autonomously, intrinsic motivation is substituted by these external interventions. The locus of control shifts from inside to outside the person (Rotter 1966). The person in question no longer feels responsible but makes the outside intervention responsible instead. However, this shift in the locus of control only takes place when the intervention is considered to be controlling. In contrast, when the intervention is perceived to be supportive, in the sense that it acknowledges one's competence, internal control is strengthened. Intrinsic or extrinsic motivation is raised depending on which aspect is more prominent.

(2) Reciprocity is violated. The implicit contract based on mutual acknowledgment of one's engagement is violated when a task undertaken by intrinsic motivation is rewarded extrinsically (Gouldner 1960, Rousseau 1995). Conversely, maintaining norms of reciprocity causes a higher willingness to contribute to a public good or prevent over-exploitation of a common pool resource.

The 'hidden cost of reward' have been generalized in economics in three dimensions:

a) All outside interventions can affect intrinsic motivation: in addition to rewards the same effect can come about by external regulations (commands and controls).

b) External interventions crowd-out intrinsic motivation if they are perceived to be controlling and they crowd-in intrinsic motivation if they are perceived to be supporting. Intrinsic motivation is bolstered by the following factors leading to the crowding-in effect: (i) Personal relationships foster intrinsic motivation. Mutual acknowledgment of one's obligations and responsibilities is appreciated among friends, colleagues and family members. Thus, team-based or community-based structures provide motivational benefits (Grant 1996, p. 118). (ii) Principals and agents communicate with each other. Communication is a precondition for reciprocity via learning about, and acknowledging the duties and responsibilities of other people. Experiments show that communication systematically raises the intrinsic motivation to cooperate (e.g. Dawes, van de Kragt and 
Orbell 1988, Frey and Bohnet 1995). (iii) Citizens participate in decision making. The greater the possibility to codetermine, the more the citizens would adopt decisions as their own. Participation thus raises self-determination and is a precondition for reciprocity.

c) Motivational crowding effects must be considered simultaneously with the relative price effect (Psychologists considered the first effect in isolation, while economists were aware of only the second effect).

The three dimensions are best analyzed in a principal-agent setting.

A (representative) agent adjusts his or her performance considering the benefits B and the cost $\mathrm{C}$ induced. Both benefits and costs increase in performance $\mathrm{P}$, i.e. $\left[\mathrm{B} / \mathrm{CP} \equiv \mathrm{B}_{\mathrm{P}}>\mathrm{C}\right.$, and $\left[\mathrm{C} / \mathrm{L} \equiv \mathrm{C}_{\mathrm{P}}>\mathrm{C}\right.$. Higher performance exhibits diminishing marginal returns $\left(\mathrm{B}_{\mathrm{PP}}<0\right)$ and has increasing marginal cost $\left(\mathrm{C}_{\mathrm{PP}}>0\right)$. Benefits and cost are also influenced by the principal's external intervention $\mathrm{E}$

$$
\begin{aligned}
& \mathrm{B}=\mathrm{B}(\mathrm{P}, \mathrm{E}) ; \mathrm{B}_{\mathrm{P}}>0, \mathrm{~B}_{\mathrm{PP}}<0 ; \\
& \mathrm{C}=\mathrm{C}(\mathrm{P}, \mathrm{E}) ; \mathrm{C}_{\mathrm{P}}>0, \mathrm{C}_{\mathrm{PP}}>0 .
\end{aligned}
$$

A rational agent chooses that level of performance $\mathrm{P}^{*}$ that maximizes net benefits $(\mathrm{B}-\mathrm{C})$ which yields the first-order condition

$$
\mathrm{B}_{\mathrm{P}}=\mathrm{C}_{\mathrm{P}}
$$

Differentiating this utility maximizing condition with respect to E shows how the agent's optimal performance $\mathrm{P}^{*}$ is affected when the principal changes the extent of external intervention

$$
\begin{aligned}
& \mathrm{B}_{\mathrm{PE}}+\mathrm{B}_{\mathrm{PP}} \mathrm{dP} * / \mathrm{dE}=\mathrm{C}_{\mathrm{PE}}+\mathrm{C}_{\mathrm{PP}} \mathrm{dP} * / \mathrm{dE}, \text { or } \\
& \frac{\mathrm{dP}^{*}}{\mathrm{dE}}=\frac{\mathrm{B}_{\mathrm{PE}}-\mathrm{C}_{\mathrm{PE}}}{\mathrm{C}_{\mathrm{PP}}-\mathrm{B}_{\mathrm{PP}}} \lessgtr 0 .
\end{aligned}
$$

Following standard principal-agent theory (e.g. Alchian and Demsetz 1972, Fama and Jensen 1983), external intervention raises performance by imposing higher marginal cost on shirking or, equivalently, by lowering the marginal cost of performing, $\mathrm{C}_{\mathrm{PE}}<0$. This is the relative price effect of external intervention. As the crowding effect is neglected, i.e. a change in external intervention does not affect the marginal utility of performing $\left(\mathrm{B}_{\mathrm{PE}}=0\right)$, the orthodox economic theory predicts that external intervention raises performance $(\mathrm{dP} * / \mathrm{dE}>0)$.

This positive effect is strengthened if the external intervention bolsters intrinsic motivation (crowding-in effect, $\left.\mathrm{B}_{\mathrm{PE}}>0\right)$. On the other hand, the crowding-out effect $\left(\mathrm{B}_{\mathrm{PE}}<0\right)$ and the 
relative price effect $\left(\mathrm{C}_{\mathrm{PE}}<0\right)$ of an external intervention work in opposite directions, so that the outcome $\mathrm{dP} * / \mathrm{dE}$ depends on the relative size of $\mathrm{C}_{\mathrm{PE}}$ and $\mathrm{B}_{\mathrm{PE}}$.

External interventions may moreover have an indirect damaging effect on intrinsic motivation. The crowding out effect may spread to further areas, even into those where the external intervention has not been applied. If intrinsic motivation is crowded out in areas where it is a major (or even the only) behavioral incentive, the overall outcome of an external intervention tends to be even more strongly against the principal's interest. There may thus be an indirect 'motivational spill-over effect' to be added to the direct crowding-out effect. A possible scenario can be based on policy instruments such as effluent charges or tradable permits. They work efficiently where they are applied, but an induced substitution of environmental morale by monetary incentives may well lead people to protect the environment less in areas where no external incentives exist. This undesired spill-over effect is not only a possibility with monetary incentives but also with rules and regulations.

\section{B. Empirical Evidence}

Crowding theory has been the subject of such a large number of laboratory experiments that it is impossible to summarize their results here. Fortunately, there have already been no fewer than five formal meta-analytical studies relating to the crowding theory.

Rummel and Feinberg (1988) used 45 experimental studies covering the period 1971-85; Wiersma (1992) 20 studies covering 1971-90; and Tang and Hall (1995) 50 studies from 1972-92. These meta-analyses essentially support the cognitive evaluation theory developed by Deci and his co-workers where intrinsic motivation is undermined if the externally applied rewards are perceived to be controlling by the recipients. This by now "conventional" view was challenged by Cameron and Pierce (1994) and Eisenberger and Cameron (1996) who on the basis of their own meta-analysis covering studies published in the period 1971-1991 (the two studies are based on a virtually identical set of studies) concluded that the undermining effect is largely "a myth" and that cognitive evaluation theory should therefore be abandoned. These studies attracted a great deal of attention, and many scholars on that basis seem to have concluded that no such thing as a crowding-out effect exists. Deci, Koestner and Ryan (1998) in a very extensive study were able to show that these conclusions are unwarranted and that the crowding-out effect is a robust phenomenon of significant size under the conditions identified. This most recent meta-analysis includes all the studies considered by Cameron, Pierce and Eisenberger as well as several studies which have appeared since then. The 68 
experiments reported in 59 articles span the period 1971-1997, and refer to 97 experimental effects. It turns out that tangible rewards undermine intrinsic motivation for interesting tasks (i.e. tasks for which the experimental subjects show an intrinsic interest) in a highly significant and very reliable way, and that the effect is moderately large. Tangible rewards, in particular monetary compensations, are obviously perceived to be controlling by the experimental subjects and therefore tend to crowd out intrinsic motivation. It is important to see that the experimental studies look at the net effect of a reward while we argue that the conventional relative price effect should be separated from the crowding-out effect, and that it is important to consider their relative size under various conditions.

Crowding theory has also received strong support in field studies. A case study refers, for example, to the so-called "token economies" where people living in homes for the elderly were induced to undertake certain tasks (such as making their bed) in exchange for vouchers. As a consequence, after some time, these people were only willing to do anything at all if they received a compensation. The intended activation of the aged proved to be a failure (Kazdin 1982). Crowding-out has also been the subject of econometric studies. For example, in an econometric study of 116 managers in medium sized Dutch firms, Barkema (1995) found that the number of hours worked in the company decreased with the intensity of personal control effected by the superiors.

Another meta-analysis of 19 studies and 115 effect sizes for the period 1975-1995 devoted to the effects of organizational behavior modification on task performance (Stajkovic and Luthans 1997: 1141) also identifies a crowding-out effect. When a financial reward is used in combination with non-financial interventions, the monetary payment has been observed to diminish the effect of the total intervention.

The crowding-in effect is also well supported by experimental (see again Deci, Koestner and Ryan 1998) as well as field evidence. For example, an econometric analysis documents the positive effect of political participation possibilities on intrinsic motivation in the form of civic virtue (Frey 1997b): Keeping many other influences constant, the citizens in those cantons of Switzerland with more developed institutions of direct democracy have a higher level of civic virtue resulting in a lower level of tax cheating.

\section{Crowding Effects in Environmental Policy}

Individuals as consumers are of great importance for the preservation of the natural environment (see Ölander and Thogersen 1995). Firms and other private organizations, as 
well as the government sector, also play a major role in the protection and preservation of the environment. Their behavior when subjected to environmental policy can also be analyzed using crowding theory but care must be taken to aggregate the behaviour of individual decision makers to the reactions of the units themselves.

The crowding-out effect can only take place if individuals have a substantial amount of environmental morale before the external intervention occurs. It undermines environmental morale in the area where the policy intervention takes place, and/or in a related area (spillover effect). There exists abundant evidence that people are prepared to follow their environmental conscience provided the cost of doing so is not too high (particularly in low cost situations, see Kliemt 1986, Kirchgaessner 1992, Diekmann and Preisendörfer 1998). Examples are the separation of types of refuse, non-littering in public places, and the boycott of firms which damage the environment, such as choosing a rival petrol station over Shell in the case of the Brent Spar incident (see Thogersen 1994 for many further examples).

The following propositions are formulated to work out as clearly as possible the expected consequences of applying the various instruments of environmental policy. The first proposition deals with direct governmental interventions as employed in wide areas of environmental policy.

Proposition 1: An environmental policy via controls and commands (regulations) undermines environmental morale.

When government intervenes via regulations it often prescribes in great detail a particular behaviour, and threatens punishments. This shifts the locus of control away from individuals. Consumers' self-determination is reduced and they feel that to exercise high environmental morale is superfluous. On the other hand, the use of the legal system to influence behavior has an expressive function. The citizens are clearly informed that an environmentally friendly behavior is expected of them. Such affirmation tends to reinforce existing environmental morale.

In order to see the outcome on behavior in the case of an intervention that is perceived as controlling, it is necessary to compare the crowding-out effect to the countervailing relative price effect. The latter is induced by an expected cost of punishment if environmental regulations are violated. Individuals are punished only if their deviant behavior is detected, if they are convicted, and if they are actually punished with a fine or imprisonment. Thus, many steps have to be taken, and there are many interventions possible in the form of outright 
bribes or calling upon political conveniences before a punishment is really effected. Especially with regard to the environment, it is often difficult to prove that a regulation has been violated so that punishments tend to be of small magnitude and delayed. It is, moreover, well known that individuals find it difficult to deal rationally with the probabilities involved (Kahneman, Slovic and Tversky 1982, Dawes 1988, Thaler 1992) so that the underlying calculus of expected punishment leads to uncertain behavioral consequences (Schoemaker 1982). It follows that the implicit relative price effect induced by controls and commands is in general rather limited.

The relative size of the countervailing effects of crowding-out environmental morale and regulations depends on the specific situation. The more strongly induced environmentally friendly behavior is, and the more the expressive function of the law strengthens existing environmental morale, the less regulations reduce individuals' discretionary room, and the more consistently obvious violators are punished. This is best achieved with a few, easy to understand regulations where punishments fit the damage done to nature. A large number of complex, abstract, and opaque regulations, on the other hand, are unlikely to improve the environment as environmental morale will be strongly crowded out while threatened punishments are easier to evade.

The next two propositions deal with environmental instruments preferred by economists because they explicitly affect the monetary incentives faced by consumers (see e.g. Stavins 1998).

Proposition 2: Tradeable emission rights tend to strongly crowd-out environmental morale.

Tradeable emission rights fix the quantity of pollution (see e.g. Tietenberg 1985). The environment may thus be burdened only in so far as the emitter is licensed to do so by the emission rights in his or her possession. The trade between prospective polluters results in a price for the pollution rights. While this instrument has been devised for, and so far has been applied to firms, it may also be used to curb the pollution caused by private households. The basic idea is that the property rights to nature belong to society as a whole (and are administrated by the government), and that its use is no longer free of charge but that a price has to be paid. The scheme thus effects a change in relative prices and induces a change in behavior based on extrinsic motivation.

To pay for being able to undertake an undesired activity - the pollution of the natural environment - can be compared with indulgencies sold in the Middle Ages (Goodin 1994). 
Such trades foster a cynical attitude, conveying the notion that it is acceptable to sin, provided you pay for it. The sense of punishment for sinning is at least partly lost. The exchange and bargaining process between the buyers and sellers of emission rights focuses the attention on the possibilities to pollute thereby acquired. In this particular sense, the polluter has been conferred a 'license to pollute' (see Kelman 1981). The use of the price system is accompanied by a process whose expressive connotations suggest that owners of these rights can legitimately pollute the environment (Blinder 1987). Conversely, to refrain from damaging the environment for a moral reason plays no role, or is even taken to be irrational or naive. These are the reasons why the use of tradeable emission rights is expected to lead to a strong crowding out of environmental morale.

The relative price and the crowding out effect work in opposite directions. Emission rights tend to reduce pollution because they make violation costly but at the same time the exact mechanism producing this result tends to markedly destroy the intrinsic motivation to safeguard the environment.

This negative effect on environmental morale is also expected in the case of a second preferred instrument by economist, environmental taxes.

Proposition 3: Environmental taxes (emission charges) tend to crowd out environmental morale but the effect is smaller than in the case of tradeable emission rights.

Environmental taxes fix the cost of polluting by government decree. Unlike tradeable emission rights this instrument directly imposes charges on those consumers (and firms) damaging nature. While the mechanism for calculating a particular price differs, the extrinsically induced change of behavior is identical. But the expressive connotation is quite different. To charge for the use of the environment makes it clear that it is an undesired activity better not to be undertaken. There is still a crowding-out effect to be expected because the government's intervention reduces the extent of individuals' self-determination. The locus of control is shifted to the government, and consumers are induced to feel that they are no longer responsible for protecting nature. The expressive connotation in the case of environmental taxes is clearly less destructive to environmental morale than are tradeable emission rights. As the relative price effect is of the same magnitude with both instruments (given the same cost for polluting is imposed), but crowding-out is expected to be less marked, emission taxes are in general more effective in protecting the environment than are tradeable emission rights. The exact size of the crowding-out effect connected with 
environmental taxes depends on a variety of circumstances. On the basis of the considerations just discussed it is, however, possible to advance a proposition comparing the effect of different tax rates.

Proposition 4: Either "low" or "high" environmental tax rates are more effective than "intermediate" tax rates.

Low environmental taxes work because they have a clear expressive function which supports environmental morale. Because taxes are low, consumers do not feel they are strongly controlled by this instrument so that the crowding-out effect is small or may even turn into a crowding-in effect due to the expressive aspects of the tax (but the relative price effect is, of course, also low). There exists empirical evidence suggesting that low environmental taxes work well under these conditions (see e.g. Thogersen 2003 for small differentiated garbage fees).

High environmental taxes work because a strong relative price effect is induced: it becomes very costly to pollute nature. This effect is likely to dominate the crowding-out effect of taxation especially when environmental morale is low from the very beginning.

An intermediate sized environmental tax induces undesirable effects on both accounts. Environmental morale is crowded-out as individuals' self-determination becomes noticeably impaired but the tax rates are insufficient to induce much reduction in pollution due to extrinsic motivation. This proposition has been empirically supported for the case of positive incentives in an article with the suggestive title "Pay Enough or Don't Pay at All" (Gneezy and Rustichini 2000). The study is about daycare centers confronted with the problem that parents sometimes arrive late to pick up their children which forces teachers to stay after the official closing time. A typical economic approach would suggest introducing a fine for collecting children late. Such a punishment is expected to induce parents to reduce the occurrence of belatedly picking up their children. In the study, they first recorded the number of late-coming parents over a particular period of time. In a second period extending over twelve weeks, a significant monetary fine for collecting children late was introduced. After an initial learning phase, the number of late-coming parents increased substantially, which is consistent with the crowding-out effect. The introduction of a monetary fine transformed the relationship between parents and teachers from a non-monetary into a monetary one. As a result, the parents' intrinsic motivation to keep to the time schedules was reduced or was crowded out altogether; the feeling now was that the teachers are "paid" for the disamenity of 
having to stay longer. That parents' intrinsic motivation was crowded out for good by the introduction of a penalty system is supported by the fact that the number of late-coming parents remained stable at the level prevailing even after the fine was cancelled in a third phase.

The following two propositions show how various policy instruments produce a crowding-in effect to preserve nature.

Proposition 5: Environmental morale is supported in the short term by appeals and participation, and in the long term by education

These outside interventions strengthen consumers' self-determination. The locus of control remains with the individuals as these measures - at least if well done - emphasize their own responsibility. This crowding-in effect may be restricted to a particular area addressed by an intervention, but is likely to extend beyond that if individuals perceive a substantial degree of similarity of issue and content.

There exists substantial empirical evidence that these short and long run interventions do indeed motivate consumers to change their behavior. Examples are appeals to save water in times of drought (e.g. Baumol and Oates 1979: 296-9) or recycling (e.g. De Young 1985-6, Hopper and Nielsen 1991, see more generally Thogersen 1994).

To undertake an environmental policy based on the respective intrinsic motivation has strong limitations. There are two major aspects to be considered.

(1) Environmental morale can only be evoked and targeted to reach a specific goal if the contribution expected by the consumers are easy to comprehend and correspond to common sense. This is true for some environmental problems but certainly not for all. Often, the damage done to the environment by a good or service is hidden and occurs at earlier stages of production not visible in the commodity itself (e.g. a good which looks environmentally clean may cause heavy pollution because of the way it is transported to the stores).

(2) Environmental morale may be unreliable and unsustainable. It may, in particular, suddenly drop when consumers realize that other persons take advantage of their environmentally responsible behavior. This "sucker" effect corresponds to everyday observations and has been well documented in prisoners' dilemma experiments (e.g. Dawes, McTavish and Shaklee 1977, Ledyard 1995). There is also strong empirical evidence (Diekmann and Preisendörfer $1992,1998)$ that individuals consistently follow their intrinsic motivation only as long as the 
cost is not substantial (for so-called 'low cost decisions' see Kliemt 1986, Kirchgässner 1992, and especially for the environment Frey 1997a). A typical low cost decision is voting - where as stated in the introduction - environmental morale is crucial to having the governments' respective policies sanctioned.

It follows that an environmental policy solely based on people's intrinsic motivation would be misguided and ineffective. Environmental morale is, however, an indispensable element needed in an overall policy effort, and in particular to accompany the application of marketbased instruments.

Proposition 6: Environmental morale is supported and raised by the expressive function of legal regulations.

Such regulations differ strongly from the control and command type of legal interventions. Punishment for non-observers is sometimes not even mentioned, or plays a small role (e.g. it is irrelevant whether there is a good chance of being able to apply a punishment). The main function of the law in this case is to emphasize a certain direction - for desired behavior to protect the environment - and to express it officially. While orthodox economists have disregarded this function, lawyers have always been aware of its importance (among adherents of the law and economics movement e.g. Cooter 1984, 1994, Sunstein 1997).

The final proposition remains open with regard to the effect on intrinsic motivation.

Proposition 7: Government subsidies have an ambiguous effect on environmental morale.

On the one hand, environmental morale might be supported by government subsidies. This is the case if subsidies for activities reducing pollution serve an expressive function. Government policy indicates what is considered desirable behavior. The monetary transfers as such corroborate the change in behavior due to the change in relative prices. The relative price and the crowding effect work in the same direction.

For various other reasons, environmental subsidies are, however, no ideal policy instrument. To mention only a few problems: (i) Subsidies are often handed out independent of the reduction of pollution so that there is no marginal extrinsic incentive effect. In this case, the beneficial effect must come solely from crowding in environmental morale. But as the subsidy is not targeted, and money as such does not talk, the expressive effect is likely to be minor. (ii) Subsidies effecting a change in relative prices provide an incentive to increase pollution before their introduction so that the recipients can benefit even more from the 
subsidy. (iii) Subsidies are a drain on government revenues. The good achieved by the inducements must be compared to the costs imposed on individuals by the necessary taxation. The size of these 'dead weight cost' depends on a number of conditions but some studies have calculated a rather high burden (e.g. Stuart 1984) so that this aspect cannot be treated lightly.

On the other hand, government subsidies are expected to undermine environmental morale if they are perceived as (controlling) bribes. A case in point is compensation offered to host socalled locally unwanted projects. (Frey and Oberholzer-Gee 1997). This siting problem is known as the 'Not in my backyard' or NIMBY-problem. For many different projects and major capital investments, a wide consensus exists that they are worth being undertaken. But no community is prepared to tolerate their vicinity. Such 'nimbyistic' behavior is well documented in cases where communities object to the siting of e.g. hazardous waste disposal facilities or the construction of freeways.

Economists have a handy tool to deal with such a situation. As the aggregate net benefits of undertaking the project are positive, one must simply redistribute them in an appropriate way. The communities which are prepared to accept the undesired project within their borders must be compensated in such a way as to make their net benefits positive (O[Hare 1977; Kunreuther and Kleindorfer 1986). This policy recommendation underestimates the true costs of price incentives in that it fails to take into account the detrimental effects of motivation crowding-out.

The hypothesis that external incentives crowd out civic duty or intrinsic motivation and therefore the willingness to accept the locally undesired project was tested by analyzing the reaction to monetary compensation offered for a nuclear waste repository (Frey and Oberholzer-Gee 1997). A survey was undertaken in Spring 1993 among the population of a region in Switzerland that was found to be ideal for hosting a NIMBY-type project. All respondents were asked if they were willing to permit the construction of a nuclear waste repository on the grounds of their community.

More than half of the respondents (50.8\%) agreed to have the nuclear waste repository built in their community, $44.9 \%$ opposed the siting, and $4.3 \%$ did not care where the facility was built. Thus, this unfavorable siting decision is widely accepted in spite of the fact that a nuclear waste repository is mostly seen as a heavy burden for the residents of the host community. In a next step the level of external compensation was varied. To this end the respondents were asked the same questions whether they were willing to accept the 
construction of a nuclear waste repository. This time, however, it was added that the Swiss parliament had decided to compensate all residents of the host community. The amount offered was varied from CHF 2500 per individual and year $(\mathrm{N}=117)$, to CHF $5000(\mathrm{~N}=102)$, and CHF $7500(\mathrm{~N}=86)^{2}$. While $50.8 \%$ of the respondents agreed to accept the nuclear waste repository without compensation, the level of acceptance drops to $24.6 \%$ when compensation is offered. The amount of compensation has no significant effect on the level of acceptance. About one quarter of the respondents seem to reject the facility simply because financial compensation is attached to it.

Compensation fundamentally alters the perceived nature of a siting procedure. What was observed in the analysis of verbal behavior represents precisely the type of mechanism postulated by motivation crowding theory. While external intervention, i.e. offering compensation, manages to address concerns regarding the costs of a noxious facility, it reduces the intrinsic motivation to permit the construction of such a facility. In the case studied, this latter effect even outweighs the benefits of external intervention, thereby reducing overall acceptance.

\section{Concluding Remarks}

Environmental morale and motivation affect individuals' behavior as potential polluters, users of common pool resources, consumers of environmental friendly products, workers, investors, environmental activists, donors or volunteers of environmental organization, voters on environmental issues and fellow citizens monitoring and sanctioning other polluters. Two kinds of behavioral effects are expected: First, environmental morale is often associated with pro-environmental attitudes or preferences that increase the demand for a clean environment. The result is a common demand effect for private environmental goods and reflected in market prices. There is substantial evidence for the willingness-to-pay for a clean environment from hedonic market studies on the housing and labor market. Second and probably more important, environmental morale helps to overcome the free rider problem that is pervasive with the provision of a clean environment. Intrinsically motivated people voluntarily contribute to public environmental goods, at least if others contribute too, and are willing to bear costs to punish fellow citizens who do not cooperate. The latter points to the

\footnotetext{
${ }^{2}$ The compensation offered here was quite substantial. Median household income for the respondents was CHF 5250 per month.
} 
importance of social interaction or social capital in the provision of local environmental goods (see, e.g. Pretty and Ward 2001).

We briefly mention two directions for future interdisciplinary research on environmental morale that seem most interesting to us:

First, while there is a theoretical basis and preliminary evidence for the important interaction of environmental policy and individuals' environmental morale, we are still far away from a robust understanding of motivational interactions. Much additional empirical evidence is needed e.g. How do deposits or their abolishment affect recycling? What is the effect of "green" gasoline taxes on recreational traffic beyond the price effect? to mention just two areas of potential enquiry.

Second, under what conditions do firms' managers make environmental friendly decisions? There are, of course, reputation and other economic arguments. For example, firms are willing to bear costs to reduce environmental externalities if they can avoid consumer boycotts. The latter is more likely in a competitive market. With competition, consumers can easily switch to alternative suppliers at a low cost to themselves. In addition to this indirect effect of consumers' environmental morale, there might, however, also be direct consequences of managers' motivation on business decisions. So far, any links between environmental morale and corporate environmental responsibility are not well understood but might well rely on similar aspects of discourse as on the community level (see Scherer and Palazzo 2005 for corporate social responsibility in general).

Overall, environmental morale and motivation are found to be necessary for the successful solution of cooperation problems in the environmental realm. In institutional and policy design, this has to be taken actively into account as environmental morale cannot be understood as an invariant individual preference. It follows that institutions have to be designed so that environmental morale is sustained or strengthened rather than made superfluous and crowded out. Environmental morale and motivation thus have to remain high on the research agenda of interdisciplinary social scientists. 


\section{References}

Alchian, Armen A. and Harold Demsetz (1972). Production, Information Costs and Economic Organization. American Economic Review 62(5): 777-795.

Andreoni, James (1988). Privately Provided Public-Goods in a Large Economy - the Limits of Altruism. Journal of Public Economics 35(1): 57-73.

Andreoni, James (1990). Impure Altruism and Donations to Public-Goods - a Theory of Warm-Glow Giving. Economic Journal 100(401): 464-477.

Andreoni, James and Rachel Croson (2008). Partners versus Strangers: Random Rematching in Public Goods Experiments. Forthcoming in: Charles R. Plott and Vernon L. Smith (eds). Handbook of Experimental Economic Results. Amsterdam: North Holland.

Arrow, Kenneth J. (1971). Political and Economic Evaluation of Social Effects and Externalities. In: Michael D. Intriligator (ed.). Frontiers of Quantitative Economics, Vol. I. Amsterdam: North Holland.

Barkema, Harry G. (1995). Do Executives Work Harder When They Are Monitored? Kyklos 48(1): 19-42.

Baumol, William J. and Wallace E. Oates (1979). Economics, Environmental Policy, and the Quality of Life. Englewood Cliffs, N.J.: Prentice-Hall.

Becker, Gary S. (1976). The Economic Approach to Human Behavior. Chicago: Chicago University Press.

Bénabou, Roland and Jean Tirole (2003). Intrinsic and Extrinsic Motivation. Review of Economic Studies 70(3): 489-520.

Biel, Anders, Chris von Borgstede and Ulf Dahlstrand (1999). Norm Perception and Cooperation in Large-Scale Social Dilemmas. In: Margaret et al. Foddy (ed.). Resolving Social Dilemmas Dynamic, Structural, and Intergroup Aspects. London: Psychology Press: 388.

Blinder, Alan S. (1987). Hard Heads, Soft Hearts. Reading: Addison-Wesley.

Bohnet, Iris and Bruno S. Frey (1999). The Sound of Silence in Prisoner's Dilemma and Dictator Games. Journal of Economic Behavior and Organization 38(1): 43-57.

Cameron, Judy and W. David Pierce (1994). Reinforcement, Reward, and Intrinsic Motivation: A Meta-Analysis. Review of Educational Research 64 (Fall): 363-423.

Coleman, James S. (1990). Foundations of Social Theory. Cambridge, MA: Belknap Press of Harvard University Press.

Cooter, Robert D. (1984). Prices and Sanctions. Columbia Law Review 84: 1523-60.

Cooter, Robert D. (1994). Laws and Prices: How Economics Contributed to Law by Misunderstanding Morality. Working Paper No. 94-2, Program in Law and Economics, University of California at Berkeley.

Cropper, Maureen L. and Wallace E. Oates (1992). Environmental Economics: A Survey. Journal of Economic Literature 30 (June): 675-740.

Dawes, Robyn M. (1988). Rational Choice in an Uncertain World. San Diego and New York: Harcourt, Brace, Yovanovich.

Dawes, Robyn M., Alphons J.C. van de Kragt and John M. Orbell (1988). Not Me or Thee but WE: The Importance of Group Identity in Eliciting Cooperation in Dilemma Situations - Experimental Manipulations. Acta Psychologica 68: 83-97. 
Dawes, Robyn M., Jeanne McTavish and Harriet Shaklee (1977). Behavior, Communication, and Assumptions about Other People's Behavior in a Commons Dilemma Situation. Journal of Personality and Social Psychology 35: 1-11.

De Young, R. (1985/86). Encouraging Environmentally Appropriate Behavior: The Role of Intrinsic Motivation. Journal of Environmental Systems 15: 281-292.

Deci, Edward L. (1971). Effects of Externally Mediated Rewards on Intrinsic Motivation. Journal of Personality and Social Psychology 18 (1): 105-15.

Deci, Edward L. and Richard M. Ryan (1985). Intrinsic Motivation and Self-Determination in Human Behaviour. New York: Plenum Press.

Deci, Edward L., Richard Koestner and Richard M. Ryan (1998). Extrinsic Rewards and Intrinsic Motivation: A Clear and Consistent Picture After All. Mimeo, Department of Psychology, University of Rochester.

Diekmann, Andreas and Peter Preisendörfer (2003). Green and Greenback: The Behavioral Effects of Environmental Attitudes in Low-Cost and High-Cost Situations. Rationality and Society 15(4): 441-472.

Eisenberger, Robert and Judy Cameron (1996). Detrimental Effects of Reward. Reality of Myth? American Psychologist 51 (Nov): 1153-1166.

Falk, Armin and Urs Fischbacher (2006). A Theory of Reciprocity. Games and Economic Behavior 54(2): 293-315.

Fama, Eugene F. and Michael C. Jensen (1983). Separation of Ownership and Control. Journal of Law and Economics 26: 301-351.

Faulhaber, Gerald R. and William J. Baumol (1988). Economists as Innovators. Journal of Economic Literature 26 (2): 577-600.

Fehr, Ernst and Simon Gächter (2000a). Cooperation and Punishment in Public Goods Experiments. American Economic Review 90(4): 980-994.

Fehr, Ernst and Simon Gächter (2000b). Fairness and Retaliation: The Economics of Reciprocity. Journal of Economic Perspectives 14(3): 159-81.

Feld, Lars P. and Bruno S. Frey (2002). Trust Breeds Trust: How Taxpayers Are Treated. Economics of Governance 3(3): 87-99.

Frey, Bruno S. (1992a). Economics as a Science of Human Behaviour. Boston and Dordrecht: Kluwer.

Frey, Bruno S. (1992b). Tertium Datur: Pricing, Regulating and Intrinsic Motivation. Kyklos 45(2): 161-84.

Frey, Bruno S. (1997a). A Constitution for Knaves Crowds Out Civic Virtues. Economic Journal 107 (July): 1043-1053.

Frey, Bruno S. (1997b). Not Just for the Money. An Economic Theory of Personal Motivation. Cheltenham, U.K. and Brookfield, USA: Edward Elgar.

Frey, Bruno S. and Felix Oberholzer-Gee (1997). The Cost of Price Incentives: An Empirical Analysis of Motivation Crowding-Out. American Economic Review 87(4): 746-755.

Frey, Bruno S. and Iris Bohnet (1995). Institutions Affect Fairness: Experimental Investigations. Journal of Institutional and Theoretical Economics 151(June): 286-303.

Frey, Bruno S. and Stephan Meier (2004). Social Comparisons and Pro-Social Behavior: Testing "Conditional Cooperation" in a Field Experiment. American Economic Review 94(5): 1717-1722. 
Gächter, Simon (2006). Conditional Cooperation: Behavioral Regularities from the Lab and the Field and Their Policy Implications. Mimeo, University of Nottingham.

Gächter, Simon and Ernst Fehr (1999). Collective Action as a Social Exchange. Journal of Economic Behavior and Organization 39(4): 341-69.

Gneezy, Uri and Aldo Rustichini (2000). Pay Enough or Don't Pay at All. Quarterly Journal of Economics 115: 791-810.

Goodin, Robert E. (1994). Selling Environmental Indulgences. Kyklos 47: 573-596.

Gouldner, Alvin Ward (1960). The Norm of Reciprocity: A Preliminary Statement. American Sociological Review 25: 161-178.

Grant, R.M. (1996). Toward a Knowledge-based Theory of the Firm. Strategic Management Journal 17 (Winter Special Issue): 109-122.

Hahn, Robert W. (1989). The Political Economy of Environment Regulation: Towards a Unifying Framework. Public Choice 65: 21-47.

Hardin, Russell (1971). Collective Action as an Agreeable n-Prisoners' Dilemma. Behavioral Science 16(5): 472-481.

Holländer, Heinz (1990). A Social Exchange Approach to Voluntary Cooperation. American Economic Review 80(5): 1157-67.

Hopper, J.R. and J.M. Nielsen (1991). Recycling as Altruistic Behavior. Normative and Behavioral Strategies to Expand Participation in a Community Recycling Program. Environment and Behavior 23: 195-220.

Kahneman, Daniel; Paul Slovic and Amos Tversky (eds) (1982). Judgement under Uncertainty: Heuristics and Biases. Cambridge: Cambridge University Press.

Kazdin, Alan E. (1982). The Token Economy: A Decade later. Journal of Applied Behavioural Analysis 15: 431-445.

Kelman, Steven (1981). What Price Incentives? Economists and the Environment. Boston: Auburn.

Kerr, Norbert L. (1995). Norms in Social Dilemmas. In: David A. Schroeder (ed.). Social Dilemmas: Perspectives on Individuals and Groups. Westport, Connecticut: Praeger: VIII, 228.

Keser, Claudia and Frans van Winden (2000). Conditional Cooperation and Voluntary Contributions to Public Goods. Scandinavian Journal of Economics 102(2): 23-39.

Kirchgässner, Gebhard (1992). Towards a Theory of Low-Cost Decisions. European Journal of Political Economy 8: 305-320.

Kliemt, Hartmut (1986). The Veil of Insignificance. European Journal of Political Economy 2/3: 333-344.

Kunreuter, Howard and Paul R. Kleindorfer (1986). A Sealed-bid Auction Mechanism for Siting Noxious Facilities. American Economic Review 76 (May): 295-299.

Le Grand, Julian (2003). Motivation, Agency and Public Policy: Of Knights and Knaves, Pawns and Queens. Oxford: Oxford University Press.

Ledyard, John O. (1995). Public Goods: A Survey of Experimental Research. In: John Kagel and Alvin E. Roth (eds), Handbook of Experimental Economics. Princeton: Princeton University Press: 111-194.

Manski, Charles F. (2000). Economic Analysis of Social Interactions. Journal of Economic Perspectives 14(3): 115-36. 
Meier, Stephan (2006). The Economics of Non-Selfish Behaviour: Decisions to Contribute Money to Public Goods. Cheltenham: Edward Elgar.

Nyborg, Karine and Mari Rege (2003). Does Public Policy Crowd Out Private Contributions to Public Goods? Public Choice 115(3-4): 397-418.

O'Hare, Michael (1977). Not On My Block You Don't: Facility Siting and the Strategic Importance of Compensation. Public Policy 25: 409-458.

Ölander, Folke and John Thogersen (1995). Understanding of Consumer Behaviour as a Prerequisite for Environmental Protection. Journal of Consumer Policy 18: 345-385.

Olson, Mancur (1965). The Logic of Collective Action: Public Goods and the Theory of Groups. Cambridge, MA: Harvard University Press.

Ostrom, Elinor (2000). Collective Action and the Evolution of Social Norms. Journal of Economic Perspectives 14(3): 137-158.

Pittman, Thane S. and Jack F. Heller (1987). Social Motivation. Annual Review of Psychology 38: 461-89.

Pretty Jules N. and Ward Hugh (2001). Social Capital and the Environment. World Development 29(2): 209-227.

Rosseau, D.M. (1995). Psychological Contracts in Organizations. Understanding Written and Unwritten Agreements. Thousand Oaks: Sage.

Rotter, Julian B. (1966). Generalized Expectancies for Internal versus External Control of Reinforcement. Psychological Monographs 80 (1, Whole No. 609).

Rummel, A. and R. Feinberg (1988). Cognitive Evaluation Theory: A Meta-Analytic Review of the Literature. Social Behavior and Personality 16: 147-164.

Ryan, Richard M. and Edward L. Deci (2000). Self-Determination Theory and the Facilitation of Intrinsic Motivation, Social Development, and Well-Being. American Psychologist 55(1): 68-78.

Scherer, Andreas G. and Guido Palazzo (2005). The Political Role of Business in Society Corporate Social Responsibility Seen from a Habermasian Perspective. Mimeo, University of Zurich.

Schoemaker, Paul J. (1982). The Expected Utility Model: Its Variants, Purposes, Evidence and Limitations. Journal of Economic Literature 20 (June): 529-563.

Schwartz, Shalom H. (1977). Normative Influences on Altruism. New York: Academic Press.

Schwartz, Shalom H. and Judith A. Howard (1984). Internalized Values as Motivators of Altruism. In: Ervin Staub, Daniel Bar-Tal, Jerzy Karylowski and Janusz Reykowski (eds). Development and Maintenance of Prosocial Behavior, vol. 189-211. New York: Plenum.

Stajkovic, Alexander D. and Fred Luthans (1997). A Meta-Analysis of the Effects of Organizational Behavior Modification on Task Performance, 1975-95. Academy of Management Journal 40: 1122-1149.

Stavins, Robert N. (1998). Economic Incentives for Environmental Regulation. In: Peter Newman (ed.), The New Palgrave Dictionary of Economics and the Law, Vol. 2. London: Macmillan: 6-13.

Stavins, Robert N. (ed.) (2005). Economics of the Environment: Selected Readings, Fifth Edition. New York: W. W. Norton. 
Stern, Paul C., Thomas Dietz, Linda Kalof and Gregory A. Guagnano (1995). Values, Beliefs, and Proenvironmental Action - Attitude Formation toward Emergent Attitude Objects. Journal of Applied Social Psychology 25(18): 1611-1636.

Stern, Paul C., Thomas Dietz, Troy Able, Gregory A. Guagnano and Linda Kalof (1999). A Value Belief Norm Theory of Support for Social Movements: The Case of Environmentalism. Human Ecology Review 6(2): 81-97.

Stuart, Charles E. (1984). Welfare Costs per Dollar of Additional Tax Revenue in the United States. American Economic Review 74 (3): 352-362.

Sunstein, Cass R. (1997). Free Markets and Social Justice. New York: Oxford University Press.

Tang, S-H. and V. C. Hall (1995). The Overjustification Effect: A Meta-analysis. Applied Cognitive Psychology 9: 365-404.

Thaler, Richard H. (1992). The Winner's Curse. Paradoxes and Anomalies of Economic Life. New York: Free Press.

Thogersen, John (1994). Monetary Incentives and Environmental Concern. Effects of a Differentiated Garbage Fee. Journal of Consumer Policy 17: 407-442.

Thogersen, John (2003). Monetary Incentives and Recycling: Behavioural and Psychological Reactions to a Performance-Dependent Garbage Fee. Journal of Consumer Policy 26(2): 197-228.

Thogersen, John (2006). Norms for Environmentally Responsible Behaviour: An Extended Taxonomy and a Preliminary Assessment. Mimeo, Aarhus School of Business, Aarhus, Denmark.

Tietenberg, Tom (1985). Emissions Trading: An Exercise in Reforming Pollution Policy. Washington DC: Resources for the Future.

Tyler, T. R. (1990). Why People Obey the Law. Hew Haven: Yale.

Wiersma, Uco J. (1992). The Effects of Extrinsic Rewards on Intrinsic Motivation: A MetaAnalysis. Journal of Occupational and Organizational Psychology 65: 101-14. 